\title{
Современная музыка
}

Иоина КОПОСОВА

\section{«ГДЕ МОРЕ ЖИЗНИ НАМ ДАРОВАЛО БЕРЕГ...» ЗАМЫСЕЛ И ЕГО РЕАЛИЗАЦИЯ В СЕДЬМОЙ СИМФОНИИ ПЕРА ХЕНРИКА НУРДГРЕНА}

Современная финская музыка Нурдгрен-композитор прошел сабогата композиторскими именами. мобытный путь стилевого развития. Одни из них уже открыты для российских исследователей и слушателей (Э. Раутаваара, К. Ахо, Э. Салменхаара, К. Саариахо и др.), другие пока остаются неизвестны. В их числе Пер Хенрик Нурдгрен ( $\rho$ ehr Henrik Nordgren, 1944-2008) - автор более 140 опусов, среди которых 8 симфоний, около 30 конџертов для различных инструментов (как академических: скрип-

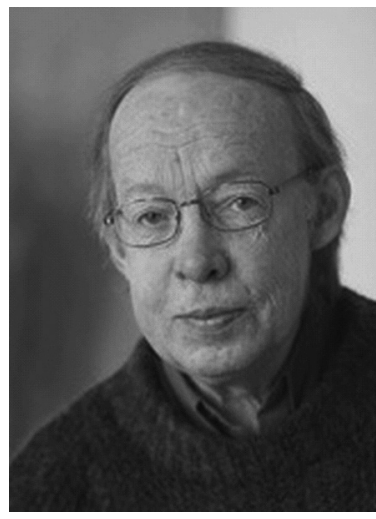

Пер Хенрик Нурдгрен

Его ранние опыты были связаны с освоением авангардного комплекса средств, в первую очередь, лигетиевой техники поля, отталкиваясь от которой, он создал собственный вариант 12-тонової техники, названный им самим «техникой мелодикополифонического кластера» (рубеж 1960-1970-х годов). Их сменило присушее многим европейским композиторам того времени разочаровака, альт, виолончель, гобой, ние в авангардной эстетике, совпавшее труба, кларнет и т. д., так и традиџионных: финское кантеле, японские сякухати, сямисен, кото), 11 струнных квартетов; оперы «Черный монах» (по А.П. Чехову) и «Алекс» ${ }^{1}$. с разносторонним и глубоким интересом к финскому фольклору, с которым оказался связан нурдгреновский оригинальный вариант упрощения стиля. $\mathrm{O}$ своих опытах в этом на-

${ }^{1}$ К этому следует добавить, что Нурдгрен был также заметным музыкальнообщественным деятелем - организатором и художественным руководителем фестиваля камерной музыки в Каустинене, а также основателем общества Шостаковича в Финляндии (2001). 
правлении композитор впоследствии говорил: «Я пытался соединить элементы народной музыки с кластерной техникой, которую тогда применял» [6, с. 37]. Дальнейшее упрошение приблизило стилистику Нурдгрена к минималисткой (середина 1980-х), наконеџ, зрелые сочинения композитора отличает своеобразный комплексный стиль, сочетающй разные элементы.

$\mathrm{He}$ менее самобытен и творческий путь финского автора. Недостаточное владение фортепиано (юношей он учился как скрипач) не позволило Нурдгрену поступить в Академию Сибелиуса. С 1964 по 1967 год, обучаясь на факультете музыкологии Хельсинского университета, он занимался композиџией частным образом с Й Ионасом Кокконеном ${ }^{1}$ (эти занятия начались в 1965-м и продолжались до 1969 года). Затем, получив грант на продолжение образования, Нурдгрен отправился не в европейские или американские авангардные џентры (как это делали все его композиторысоотечественники), а в Университет Токио, где в течение трех лет изучал японские наџиональные инструменты, а также японский опыт соединения традиџионной (фольклорной) и современной музыкальной стилистики. Здесь же продолжил занятия композиџией с Й ошио Хасегава (Yoshio Hasegawa).
После Токио Нурдгрен не возвращается в Хельсинки, а переезжает в Каустинен, центр финского фольклорного движения, где и проживет до конџа своих дней. Нурдгреновское творчество станет неким символом преодоления разрыва между академической и народной музыкой.

Для знакомства с творчеством композитора и его стилистикой мы остановились на Седьмой симфонии ор. 124 (2003). И выбор этот не случаен. Симфония - одно из последних, во многом итоговых, сочинений Нурдгрена. Она представляет собой одночастную композиџию длительностью около получаса, в значительної мере состоящую из џитатного материала, так или иначе связанного с осмыслением собственного творческого пути. И прежде всего - того важного периода (с конџа 1960-х до середины 1970-х годов), в котором, по словам самого автора, вылеплялся его собственный стиль [см.: 5]. Внутри џитатного пласта есть и чужая музыка, и фрагменты сочинений самого Нурдгрена. Поэтому задачи этого пласта многоплановы: это и показ «поля влияниї», на котором росла композиторская индивидуальность, и обозначение черт его собственного почерка.

Ведушее положение среди «чужих слов» в симфонии занимает шостаковическая монограмма «D-Es-C-H»:

\footnotetext{
${ }^{1}$ Йоонас Кокконен (Joonas Kokkonen, 1921-1996) - один из крупнейших финских композиторов после Сибелиуса, академик ФОнской Академии наук и литературы (с 1961), автор сочинений в разных жанрах, наиболее известные из которых опера «Последние искушения» (1975); Третья (1967) и Четвертая (1971) симфонии; композиџия под названием «... Durch einen Spiegel» для камерного оркестра (1977).
} 
появляясь первой среди заимствованных тем (такт 91), она неоднократно возвращается по ходу развертывания сочинения (см. ее дальнейшие проведения в тактах 130, 180, 274, 306). Особое положение этой темы быстро находит объяснение. С юных лет и до конџа жизни Шостакович оставался для Нурдгрена художественным идеалом. На склоне лет композитор скажет: «Я не в силах изменить одного факта: когда я слышу музыку Шостаковича, она неизменно глубоко трогает мою душу» [см.: 8]. 人юбовь к творчеству советского мастера у Нурдгрена сформировалась довольно рано. Его убежденным поклонником он был уже в 14-летнем возрасте ${ }^{1}$; а в годы учебы и работы в Хельсинском университете (1965-1970) исследовал особенности письма Шостаковича ${ }^{2}$ и стал крупнейшим в Ф онляндии знатоком его музыки. В собственных произведениях он плодотворно развил шостаковичевские традиџии в области оркестровки, квартетного письма, драматургии, хотя знаменитая тема-монограмма процитирована им только в Седьмой симфонии ${ }^{3}$. Ее многократные повторения в сочинении - своеобразное признание того факта, что движение Нурдгрена по композиторскому пути шло «под знаком Шостаковича».

Другие џитаты происходят из иных музыкальных пластов, но также связаны с композиторской биографией. Первый раз появляюшаяся в такте 143 Полска ${ }^{4}$ Й.Э. Таклакса, народного музыканта из Остроботнии ${ }^{5}$, отсылает нас к ранней музыке Нурдгрена. На теме этой полски, с характерным мерџанием мажорной и минорной терџий, строился финал «Портретов народных скрипачей» (Pelimannimuotokuvia, 1976) ${ }^{6}$

${ }^{1}$ Известно, что во время приезда Шостаковича в Хельсинки в 1958 году (для вручения премии имени Я. Сибелиуса), Нурдгрен спеџиально ходил на вокзал, чтобы увидеть своего кумира [см.: 5].

${ }^{2} \mathrm{~B}$ период написания дипломной работы, которая была посвяшена особенностям оркестровки Шостаковича, Нурдгрен даже приезжал в Москву для получения необходимых материалов. ${ }^{3}$ В других сочинениях Нурдгрена присутствуют различные аллюзии на музыку Шостаковича. Так, один из фрагментов Второго скрипичного конџерта (1978) отсылает к началу Восьмой симфонии Шостаковича. II часть Второго альтового конџерта (1979) не случайно названа «Свидетельство» (одним из импульсов к написанию конџерта послужило знакомство Нурдгрена с изданными Соломоном Волковым мемуарами Шостаковича, как известно, имеющими такое же заглавие).

${ }^{4}$ Полска - финский и шведский народный двудольный танеџ подвижного характера.

${ }^{5}$ Й охан Эрик Таклакс (Johan Erik Taklaks, 1856-1948) - знаменитый народный музыкант, носитель традиџий скрипичного исполнительства, бытовавших в Џентральной и Западной ФОнляндии. Полски, исполняемые Таклаксом в 1930-х годах были собраны Отто Андерссоном, профессором университета г. Турку. С ними Нурдгрен познакомился в конџе 1960-х, тогда же он брал интервью у Андерссона.

${ }^{6}$ Кроме того, другие полски Таклакса использованы в Первой симфонии композитора. 
самого известного из «фольклорных» сочинений композитора. Кроме того, другие полски Таклакса использованы Нурдгреном в Первой симфонии. Поэтому полску в данном случае можно считать своего рода символом фольклорной линии творчества композитора. А поскольку увлечение фольклором имело в жизни финского автора крайне важную роль, понятным становится доминирование темы полски в тексте симфонии (см. ее последуюшие проведения в тактах 226; 300; 314; 387).

В заключительном разделе симфонии появляется еще одна заимствованная тема - «Андалузский танеџ» Г. Винклера ${ }^{1}$. В партитуре этот Фрагмент музыки в характере салонной элегической пьесы имеет посвящение Георгу Растенбергеру - скрипачу, который был первым учителем будушего композитора ${ }^{2}$. Ноты этой пьесы Нурдгрен когда-то обнаружил в домашней библиотеке своего учителя, поэтому звучание «Андалузского танца», очевидно, связано с воспоминаниями об еще одном важном человеке в творческой биографии композитора.

В симфонии присутствуют также и две автоџитаты. Они появляются в экспозиџионной фазе сочинения, после первого проведения шостаковической монограммы (такт 89). В такте 94 выделяется фрагмент, излагаемый одними струнными. Он образован контрапунктическим соединением нескольких хроматизированных разноритмичных линиі, тесно прилегающих друг к дру-

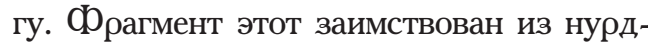
греновского Первого квартета (1967), и его фактурные особенности дают ясное представление о технике мелодикополифонического кластера, к которой композитор пришел в конџе 1960-х. А в следуюшем фрагменте (такты 104-111) солирует арфа, звучание которой приближено к японскому кото: ее партия, состоящая из последования аккордов, играется щипком у деки; сопровождает же арфу ансамбль шумовых ударных (колокольчики, тарелочки, вуд-блок). В итоге создается звеняшее, богатое обертонами характерное «японское» звучание ${ }^{3}$.

${ }^{1}$ Герхард Винклер (Gerhard Winkler, 1906-1977) - немеџкий композитор, автор многочисленных произведений популярной музыки (общим числом около 1000): песен (самая известная — «Рыбаки Капри», 1943), танџев, оперетт, музыки к кинофильмам. «Андалузский танеџ» - одна из ранних работ Винклера. Ее первая публикаџия состоялась в 1930 году. Известности музыки Винклера в Финляндии способствовала поездка композитора летом 1966 года в Норвегию и Швеџию; в Стокгольме он дирижировал оркестром Шведского радио (эта и другая информаџия находится на сайте, созданном к 100-летию композитора [см.: 4]).

2 Заниматься у Растенберга Нурдгрен начал с 13 лет.

${ }^{3} \mathrm{~K}$ сожалению, пока нет возможности сказать, какое из японских сочинений композитора здесь проџитировано, поскольку не все из них нам доступны. Сам же композитор в аннотаџии к Седьмой симфонии говорит о японском ритме этих тактов [см.: 7]. 
Автобиографическое «излучение», исходящее от џитатного материала симфонии, подытоживают два посвящения, обрамляюшие сочинение. Одно из них, находящееся в начале, обрашено к дирижеру Юхе Кангасу ${ }^{1}$, с которым Нурдгрен был связан десятилетиями плодотворной творческой дружбы². Венчает же симфонию строка, выражаюшая квинтэссенџию ее содержания: «Где море жизни нам даровало берег». Она взята из стихотворения «Маamme» Йохана Людвига Рунеберга, положенного в основу наџионального гимна С инляндии. Нурдгрен был искренне благодарен своей стране, способствовавшей его творческой реализаџии ${ }^{3}$. Поэтому использование строки из Рунеберга можно трактовать как посвящение своей стране.

Разноплановый материал, собранный вследствие особенностей замысла в рамках одного произведения, поставил перед композитором немало проблем, связанных с интонаџионной, композиџионной, содержательной џелостностью этого опуса. Попробуем понять, как они решались.

С позиџии высотной организаџии сочинение тяготеет к џентру «а»: взятый унисоном, этот звук начинает и заканчивает симфонию; ее главная тема опирается на малый минорный септаккорд от $a$; на фоне A-dur'ного трезвучия звучит монограмма D-Es-C-H (из-за этого она транспонирована на полтона выше); трезвучие от $a$ с мерџающей терџией лежит в основе полски; танеџ Винклера звучит в a-moll; не включенный в симфонию, но словно парящий над ней гимн СОинляндии написан в A-dur.

C точки зрения интонаџионных особенностей, все заимствованные темы стягиваются к двум полюсам: хроматическому (тема-монограммма и автоџитаты) и диатоническому («Андалузский танеј» и полска, хотя ее диатонический облик и «омрачен» мерџанием терџового тона). Их «примирила» главная тема симфонии, сочиненная с учетом возможности соединения этих двух начал. Она образована контрапунктическим сочетанием

\footnotetext{
${ }^{1}$ Калеви Ахо, анализируя эту симфонию, обнаруживает в ее последних тактах темумонограмму, указывающую на Юху Кангаса [2, с. 6].

${ }^{2}$ Именно благодаря Кангасу познакомившему Нурдгрена с традиџиями инструментального музицирования Џентральной Остроботнии, композитор решился на «поворот к фольклору», оба музыканта почти одновременно поселились в Каустинене, наконеј, Кангас основал Камерный оркестр Остроботнии - коллектив, исполнивший большую часть музыки композитора (в обшей сложности Кангас исполнил не менее 38 различных сочинений Нурдгрена в 370 конџертах).

${ }^{3}$ Грант от государства на обучение позволил ему овладеть профессией, последуюшие гранты, получаемые в течение жизни, дали ему возможность оставаться свободным художником (об этом и многом другом Нурдгрен пишет в статье «Быть композитором в Финляндии», вышедшей в 1995 году [см.: 6]).
} 
Таблица 1. Схема экспозиции главной темы Симфонии

\begin{tabular}{|c|c|c|c|c|c|c|c|c|c|c|c|}
\hline 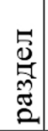 & \multicolumn{4}{|c|}{ A } & \multicolumn{2}{|c|}{$\mathbf{A}_{1}$} & $\mathbf{A}_{2}$ & \multicolumn{2}{|c|}{$\begin{array}{l}\mathbf{A}_{3 \text { конт рапункт }} \\
\text { вариантов темы }\end{array}$} & \multicolumn{2}{|l|}{$\mathbf{A}$} \\
\hline \multirow{3}{*}{$\sum_{0}^{\frac{\pi}{2}}$} & \multirow{3}{*}{ 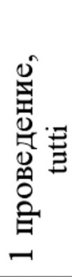 } & \multirow{3}{*}{ 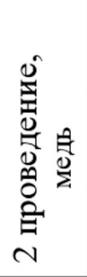 } & \multirow{3}{*}{ 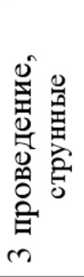 } & \multirow{3}{*}{ 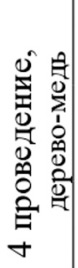 } & \multirow{3}{*}{ 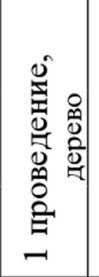 } & \multirow{3}{*}{ 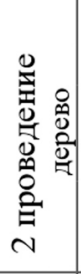 } & \multirow{3}{*}{ 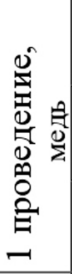 } & \multicolumn{2}{|c|}{ A, ст рунные } & \multirow{3}{*}{ 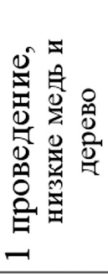 } & \multirow{3}{*}{ 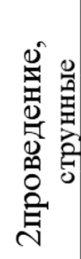 } \\
\hline & & & & & & & & \multicolumn{2}{|c|}{$\mathbf{A}_{1, \text { дерево }}$} & & \\
\hline & & & & & & & & \multicolumn{2}{|c|}{$\mathbf{A}_{2}$, медь } & & \\
\hline \multirow{2}{*}{ 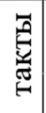 } & \multirow[t]{2}{*}{$2-5$} & \multirow[t]{2}{*}{$6-9$} & \multirow{2}{*}{$\begin{array}{l}10- \\
17\end{array}$} & \multirow{2}{*}{$\begin{array}{l}18- \\
25\end{array}$} & \multirow[t]{2}{*}{$26-33$} & \multirow{2}{*}{$\begin{array}{l}34- \\
40\end{array}$} & \multirow{2}{*}{$\begin{array}{l}41- \\
44\end{array}$} & $\begin{array}{c}1 \\
\text { проведение }\end{array}$ & $\begin{array}{c}2 \\
\text { проведение }\end{array}$ & \multirow[t]{2}{*}{$73-81$} & \multirow{2}{*}{$\begin{array}{l}82- \\
88\end{array}$} \\
\hline & & & & & & & & $45-50$ & $51-72$ & & \\
\hline
\end{tabular}

четырех хроматизированных мелодий, каждая из которых представляет свой вариант постепенного восхождения в пределах октавы. На поверку оказывается, что все мелодические линии составляют поданные в разном порядке четыре однотактовых әлемента, каждый со своим типом мелодического и ритмического движения. Эти элементы регулярно передаются из голоса в голос: таким образом, каждый такт совместного звучания собирает их в одновременности. В итоге первый четырехтакт представляет собой основної отдел 4-голосного бесконечного симметричного канона (с нулевым показателем). При этом продвижение канона, как уже сказано, опирается на малый минорный септаккорд от $a$ : на каждой сильной доле между голосами складывается его очередное обрашение (2-ї такт — квинтсекст-; 3-ё такт терџкварт-; 4-й такт - секунд- и, наконеџ, 5-ї такт - септаккорд). Таким образом, хроматика отдельных линий в этой теме «удерживается» диатониче- ской вертикалью. Идея синтеза разных начал в главной теме этим не исчерпывается, умножая ее связи с џитатным пластом сочинения. Так в ней мы найдем сочетание полифонической (бесконечный канон) и аккордово-гармонической (опора конструкции на перемешения септаккорда) организаџии; один тип указывает на тему Первого квартета, c ее техникой мелодико-полифонического кластера, а другой - на весь остальной заимствованный материал (в первую очередь, темы полски и «Андалузского танџа»).

Композиџионно-драматургические особенности, лежащие в основе главной темы, тоже отражены в сочинении в целом. Экспозиция темы-канона представляет собой довольно протяженный раздел, состоящий из нескольких этапов (см. Таблийу 1).

Здесь вслед за изложением темы, содержашим четыре проведения основного отдела канона (раздел А), следуют два ее новых варианта $\left(A_{1}\right.$ и $\left.A_{2}\right)$. Первый 
Таблицуа 2. Схема устройства Симфонии

\begin{tabular}{|c|c|c|c|c|c|c|c|c|c|}
\hline & $\mathbf{A}$ & $\mathbf{B}$ & $\mathbf{C}$ & $\mathbf{B}$ & D & B & $\mathbf{A}_{1}$ & $\mathbf{D}_{1}$ & $\mathbf{B}$ \\
\hline 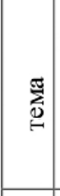 & $\begin{array}{c}\text { главная } \\
\text { тема }\end{array}$ & 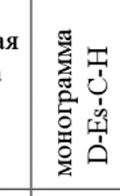 & \begin{tabular}{|c|} 
группа \\
тем- \\
автоцитат \\
(I квартет, \\
японская \\
тема) \\
\end{tabular} & 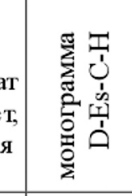 & полска & 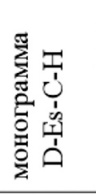 & $\begin{array}{c}\text { вариант } \\
\text { главной } \\
\text { темы }\end{array}$ & полска & 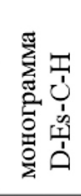 \\
\hline$\underline{\underline{z}}$ & $1-88$ & 89-93 & $94-123$ & $\begin{array}{l}124- \\
128\end{array}$ & $\begin{array}{l}143- \\
179\end{array}$ & $\begin{array}{c}180- \\
189\end{array}$ & $196-225$ & $\begin{array}{l}226- \\
273\end{array}$ & $\begin{array}{c}274- \\
290\end{array}$ \\
\hline 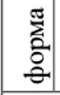 & \multicolumn{5}{|c|}{ ЭКСПозиция } & \multicolumn{4}{|c|}{ РАЗВИТИЕ } \\
\hline \multicolumn{2}{|c|}{$\mathbf{A}_{2}$} & $\mathbf{D}_{2}$ & B & $\mathbf{D}_{3}$ & \multicolumn{2}{|c|}{$\mathbf{E}$} & $\mathbf{D}_{4}$ & \multicolumn{2}{|c|}{$\mathbf{A}_{3}$} \\
\hline \multicolumn{2}{|c|}{$\begin{array}{c}\text { главная } \\
\text { тема, } \\
\text { фрагмент }\end{array}$} & $\begin{array}{c}\text { полска, } \\
\text { фрагмент }\end{array}$ & 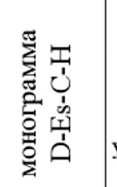 & $\begin{array}{c}\text { полска, } \\
\text { первый } \\
\text { элемент в } \\
\text { увеличении }\end{array}$ & \multicolumn{2}{|c|}{$\begin{array}{c}\text { «Андалузский } \\
\text { танец» } \\
\text { Г.Растенбергера }\end{array}$} & $\begin{array}{c}\text { полска, } \\
\text { второй } \\
\text { элемент }\end{array}$ & \multicolumn{2}{|c|}{$\begin{array}{c}\text { главная } \\
\text { тема, } \\
\text { диатонический } \\
\text { вариант }\end{array}$} \\
\hline \multicolumn{2}{|c|}{ 291-299 } & $\begin{array}{l}300- \\
305\end{array}$ & $\begin{array}{l}306- \\
313\end{array}$ & $314-360$ & \multicolumn{2}{|c|}{$361-386$} & $\begin{array}{c}387- \\
402\end{array}$ & \multicolumn{2}{|c|}{$403-432$} \\
\hline
\end{tabular}

обрашает направленность движения составляюших канон линий; во втором тема жанрово преобразуется, обретая маршевые черты. Местной кульминаџией становится контрапунктическое соединение всех уже прозвучавших вариантов (на схеме - раздел $\mathrm{A}_{3}$ ). Перечисленные проведения очевидно вытекают одно из другого, демонстрируя поступательность проџесса; последнее же $\left(\mathrm{A}_{4}\right)$, проводя музыку в исходном виде, замыкает экспозиџионный раздел, словно возвращает его движение к началу. Таким образом, логика композиџионного проџесса в экспонировании темы-канона соединяет поступательное (опирающееся на преобразования уже изложенного материала) и возвращающееся на круги своя движение.

Симфония џеликом также объединяет эти два проџесса. Ее композиџия поначалу опирается на введение все новых тем (тема-канон, монограмма «D-EsC.H», автоџитаты), потом переключается на повтор звучавшего материала: тема полски обрамлена возвращением монограммы «D-Es-C-H», затем ее повторения перемежаются с темой-каноном и полской (см. Таблииу 2). Разное качество повторения (тема-монограмма воспроизводится неизменно, две другие темы изменяются) позволяет говорить 
о сосуществовании поступательного и возвратного движения.

Изменения, происходящие с повторяемыми темами, имеют разное свойство. Полска теряет свою исходную моторность. В заключительных проведениях ее первый элемент претерпевает увеличение (раздел, обозначенный в схеме буквой $\left.\mathrm{D}_{3}\right)$, а второй изживается в длительном секвенџировании (на схеме - $\mathrm{D}_{4}$ ); тема-канон приходит к незамутненному хроматикой диатоническому звучанию (на схеме - $\mathrm{A}_{3}$ ).

Описанные процессы обозначают трехчастность композиџии в целом: ее первый раздел связан с экспонированием основных тем (такты 1-179); второї с их развитием (такты 180-290), третий представляет собой репризу с элементами развития (такты 291-432).

В заключение хотелось бы обратить внимание на то, как создается смысловое единство в этом опусе. Каким содержанием объединены столь разные темы? Автобиографический характер основного материала, казалось бы, ведет к однозначному ответу. Но сам композитор замечает, что Седьмая симфония не стала «мемуарами», несмотря на «фрагментарный характер воспоминаний со взглядом в прошлое, когда я получал вдохновение из разных источников» [см.: 7]. Многие из уже названных особенностей симфонии позволяют связать семантику составляюших ее элементов с итоговыми настроениями, с идеей прощания. Џитаты и посвящения в этом свете осмысляются как благодарность своей стране (рунеберговская цитата в конџе опуса) и духовно близким людям (Ю. Кангасу, Д.Д. Шостаковичу, Г. Растенбергеру, И.Э. Таклаксу).

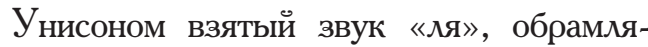
ющй сочинение, можно понимать как метафору небытия (из него рождается, в нем растворяется звучание). Наконец, особой значимостью в содержании симфонии обладает ее главная тема. Ее характерной особенностью стала опора в изложении на бесконечный (круговой) канон, благодаря которому звучание имеет весьма спеџифичный характер: тема воспринимается как остановившееся, застывшее и неподвижное, время. Своим модусом главная тема явно противостоит теме полски - моторной, имеюшей бытовую основу. Их оппозиџию, обнаженную неоднократным повторением, можно понимать как противопоставление надличного (тема-канон) и личностного (тема полски) начал. Таким образом, в самом общем плане содержание Седьмой симфонии Нурдгрена связано с вечной темой «жизнь и смерть», әстетически привлекавшей композитора на протяжении всего творческого пути ${ }^{1}$.

Итак, перед исследователем и слушателем Седьмая симфония предстает как сочинение оригинальное и по замыслу, и по реализации тех токов, которые этим замыслом обусловлены. Благодаря особенностям вне-

${ }^{1}$ Так, уже среди ранних камерных опусов Нурдгрена обнаружим «Четыре картины смерти» (Neljä kuolemankuvaa, 1968) и «Весь мир будет скорбеть» (Koko maailma valittanee, 1968; 2 -я ред. - 1974). Скорбные настроения отразились и в названии I части Третьей симфонии (1993) - Lamentations. 
музыкальної идеи опуса, его текст дает объемное представление о стилистике финского автора разных лет, о его эстетических пристрастиях, худо- жественных ориентирах и волновавших идеях, раскрывая перед нами самобытность многогранного художественного мира Пера Хенрика Нурдгрена.

\section{ЛИТЕРАТУРА} 2008.

1. Корхонен К. Композиторы Финляндии от средневековья до наших дней. Хельсинки,

2. Aho K. Symphony no.7 // Pehr Henrik Nordgren: Transient Moods: ALBACD-ABCD 288. P. 14-17.

3. Anderson M. Pehr Henrik Nordgren: Modernist composer who incorporated folk music into his work and relished his artistic freedom // The Independent. 15.10.2008.

4. Winkler G. Ein Komponistenportreit. Электронный ресурс. Режим доступа: httр:// www.capri-fischer.de

5. Heiniö M. Aikamme musiikki, 1945-1993. Porvoo, 1995 (Suomen musiikin historia 4).

6. Nordgren P.H. Being a composer in Finland // Finnish Music Quarterly. 1995. № 2. P. $36-39$.

7. Nordgren P.H. Symphony № 7 ор. 124. Электронный ресурс. Режим доступа: htt $\rho:$ / /www.fimic.fi / fimic/fimic.nsf/WWOR/51D6DA9B0D561FF7C2257555003 1C05A?opendocument\& cat=contemporary___classical

8. Schlüren Ch. The Path to the Centre // Nordic Sounds. 1995. № 3. P. 20-22.

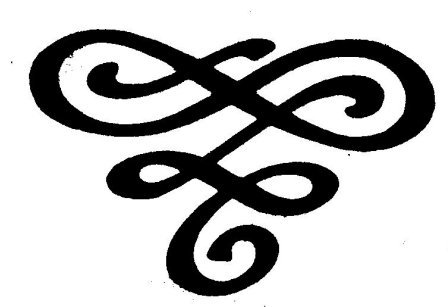

